\title{
Celebrities' Effective Presence During the Large Flood in Iran in 2019
}

\author{
Mahmoudreza Peyravi; ${ }^{1,2}$ (1) Milad Ahmadi Marzaleh, $\mathrm{PhD}^{3}$ (1)
}

1. Assistant Professor, Department of Health in Disasters and Emergencies, Health Human Resources Research Center, School of Management and Medical Informatics, Shiraz University of Medical Sciences, Shiraz, Iran

2. Research Center for Emergency and Disaster Resilience, Red Crescent Society of the Islamic Republic of Iran, Tehran, Iran

3. Student Research Committee, Department of Health in Disasters and Emergencies, Health Human Resources Research Center, School of Management and Medical Informatics, Shiraz University of Medical Sciences, Shiraz, Iran

Correspondence:

Milad Ahmadi Marzaleh

Student Research Committee

Department of Health in Disasters and Emergencies

Health Human Resources Research Center

School of Management and Medical

Informatics

Shiraz University of Medical Sciences

Shiraz, Iran

E-mail: miladahmadimarzaleh@yahoo.com

Conflicts of interest: none

Keywords: celebrity; disaster; flood; Iran; management

Received: June 4, 2019

Accepted: August 17, 2019

doi:10.1017/S1049023X1900503X
Peyravi M, Ahmadi Marzaleh M. Celebrities' effective presence during the large flood in Iran in 2019. Prehosp Disaster Med. 2019;34(6):681-682.

Letter

Dear Editor,

Occurrence of natural disasters, like floods, is followed by a lot of irreparable problems and damages. Buildings and infrastructures are destroyed and irremediable socioeconomic side effects are imposed on the communities. ${ }^{1}$ Governments essentially play key roles in managing disasters because they feature a coherent structure for organizing. They are completely familiar with social constructs and can get the related interventions done in such a way that social capitals and people-driven organizations, as dimensions of the society's resilience against disasters, can play a vital role in accelerating the rehabilitation phase if being properly guided. However, nongovernmental and/or private communities essentially influence the foresaid system in case a government is found in possession of weak management for confronting the disaster. ${ }^{2}$

Nongovernmental communities can be divided into two categories, namely personal institutions and influential individuals. Celebrities constitute one of these nongovernmental communities, which has been the major national and international sponsor of the humanitarian efforts during the past decades. In numerous events, they have shown sympathy to the pains and agonies suffered in disasters, attracted the attentions towards such social problems, and guided the capitals and resources towards charitable affairs.

Although famous people and celebrities increasingly play a key role in charity organizations, the outcomes of their participations in the incidents and calamities have been rarely discussed. ${ }^{3}$ Celebrities proved an accentuated presence for the first time in consecutive droughts in African countries. At first, they only reassured the disaster-stricken individuals through affective and psychological assistance, and the financial aids were gradually added to such heart-warming activities. ${ }^{4}$

In Iran, the majority of nongovernmental organizations do not have the authority to organize people. Therefore, famous figures and/or celebrities can get involved in humanitarian activities during catastrophes, which provokes people for help due to their popularity.

A very intensive rainfall has occurred in vast parts of Iran since March 26, 2019 that resulted in flooding in various provinces of the country. The rainfall was more severe in Khuzestan, Golestan, Lorestan, Fars, and Ilam provinces, and led to the occurrence of huge floods followed by the death of 70 individuals as well as the homelessness of a large number of people, destruction of houses, and costly damages to the urban and rural infrastructures. However, celebrities proved an active and impressive presence since the early days after the flood. The provocation and incitement of the general public's emotions for aiding the flood-stricken people was amongst the positive aspects of the celebrities' presence in the flood-stricken regions. Of course, all these activities were carried out under the supervision of Iran's Red Crescent Society (Tehran, Iran), and its bank accounts were introduced for transfer of the financial aids. Celebrities used social networks, especially Instagram (Facebook Inc.; Menlo Park, California USA), for attracting people's attentions to the flood-stricken cities and people. Celebrities also took part in delivering the financial and nonfinancial aids based on people's needs. Yet, the largest role of the celebrities in Iran's large flood was the psychological and mental support to the flood-stricken people that gave them peace of mind and tranquility. Nevertheless, celebrities are expected to support flood-stricken people in all phases of disaster management. Fortunately, people's trust in 
celebrities is growing day-in day-out, and such a capacity can be applied for managing and instigating people's contributions.

\section{Conclusion}

The celebrities' presence during the large floods in various cities of Iran featured a lot of strong points, and valuable results were attained through correct and logical management by the Red Crescent of Islamic Republic of Iran. Hence, people's pains and problems can be reduced through forming humanitarian campaigns and communities by celebrities during future disasters.

\section{Acknowledgement}

The authors would like to thank Dr. Khodadadi, the executive manager of the Red Crescent of Khuzestan province; Mr. Rezaei, the executive manager of the Red Crescent of Lorestan province; and Dr. Heravi, the executive manager of the Red Crescent of Golestan province for providing the required information. Thanks also go to Ms. A. Keivanshekouh at the Research Improvement Center of Shiraz University of Medical Sciences (Shiraz, Iran) for improving the use of English in the manuscript.

\section{References}

1. Guha-Sapir D, Hoyois P, Below R. Annual Disaster Statistical Review 2011: The Numbers and Trends. Brussels, Belgium: Centre for Research on the Epidemiology of Disasters (CRED), Institute of Health and Society (IRSS), and Universite Catholoque de Louvain, Louvain-la-Neuve; 2012.

2. Chan NW, Roy R, Lai CH, Tan ML. Social capital as a vital resource in flood disaster recovery in Malaysia. International Journal of Water Resources Development. 2019; 35(4):619-637.
3. Driessens O, Joye S, Biltereyst D. The X-factor of charity: a critical analysis of celebrities' involvement in the 2010 Flemish and Dutch Haiti relief shows. Media, Culture, E Society. 2012;34(6):709-725.

4. Richey LA, Ponte S. Better (Red $)^{\mathrm{TM}}$ than Dead? Celebrities, consumption, and international aid. Third World Quarterly. 2008;29(4):711-729. 